\title{
Intravitreal injection of low-dose gentamicin for the treatment of recurrent or persistent uveitis in horses: Preliminary results.
}

Britta M. Fischer ${ }^{1}$, Richard J. McMullen $\mathrm{Jr}^{r^{*}}$ (D), Sven Reese ${ }^{2}$ and Walter Brehm ${ }^{3}$

\begin{abstract}
Background: Despite appropriate medical therapy, many horses with equine recurrent uveitis continue to suffer from recurrent bouts of inflammation. Surgical intervention via the pars plana vitrectomy or suprachoroidal cyclosporine implant placement may control and/or prevent recurrences, however, these procedures may be contraindicated, unavailable, or declined by an owner. Thus, an effective adjunctive treatment option may help to improve the clinical outcomes in those situations. There are several anecdotal reports on the use of intravitreal gentamicin injections, but to date, no data evaluating the complication rate and/or treatment effect following this treatment have been published. Thus, the aim of this prospective study was to describe the intravitreal gentamicin injection technique, describe the associated peri-injection (within $24 \mathrm{~h}$ ) and postinjection (30 to 780 days) complications, and to report the effects of the injection on the clinical signs of uveitis. Additionally, evaluation of the systemic and ocular Leptospira-status, and its effect on the treatment outcome was performed. A total of 86 horses of various ages, breeds, and gender presenting with recurrent or persistent uveitis were treated via intravitreal injection of $4 \mathrm{mg}$ of undiluted gentamicin $(0.04 \mathrm{ml}$, Genta 100 , $100 \mathrm{mg} / \mathrm{ml}$ in 35 horses) or preservative-free gentamicin $(0.05 \mathrm{ml}, 80 \mathrm{mg} / \mathrm{ml}$ in 52 horses) under sedation and local anesthesia. All 86 horses were observed for immediate peri-injection and post-injection complications. Response to therapy was evaluated in 59 of the 86 horses (follow-up: 30 to 780 days).

Results: Peri-injection complications consisted of subconjunctival (26/86; 30.2\%) or intracameral hemorrhage (4/86; 4.7\%); both of which completely resolved within 5 days. Post-injection complications consisted of cataract formation/maturation (5/59 horses, 8.5\%) and diffuse retinal degeneration (3/59 eyes 5.1\%). The majority of horses $52 / 59$ (88.1\%) with a minimum follow-up period of 30 days were controlled (absence of recurrent or persistent inflammation) at their last recheck examination. Recurrent inflammation was documented in 5/59 (8.5\%) horses and persistent inflammation was diagnosed in 2/59 (3.4\%) horses.

Conclusions: Intravitreal injection of low-dose gentamicin shows promise at controlling different types and stages of uveitis. The ability of intravitreal injections of low-dose gentamicin ( $4 \mathrm{mg}$ ) to control persistent and recurrent inflammation warrants further investigation.
\end{abstract}

Keywords: Equine recurrent uveitis, Gentamicin, Intravitreal injection, Equine ophthalmology, Leptospira

\footnotetext{
* Correspondence: rjm0040@auburn.edu; rjmcmulljr@gmail.com

'Department of Clinical Sciences, College of Veterinary Medicine, Auburn

University, JT Vaughan Large Animal Teaching Hospital, 1500 Wire Road,

Auburn, AL 36849-5540, USA

Full list of author information is available at the end of the article
}

(c) The Author(s). 2019 Open Access This article is distributed under the terms of the Creative Commons Attribution 4.0 International License (http://creativecommons.org/licenses/by/4.0/), which permits unrestricted use, distribution, and reproduction in any medium, provided you give appropriate credit to the original author(s) and the source, provide a link to the Creative Commons license, and indicate if changes were made. The Creative Commons Public Domain Dedication waiver (http://creativecommons.org/publicdomain/zero/1.0/) applies to the data made available in this article, unless otherwise stated. 


\section{Background}

Equine recurrent uveitis (ERU) is widely recognized as an immune-mediated disease characterized either by recurrent bouts of ocular inflammation separated by variable periods of quiescence (lack of detectable ocular signs associated with active inflammation) or low-grade, persistent inflammation [1-3]. The cornerstone of treatment for ERU consists of local immunosuppression or immune-modulation in conjunction with systemic anti-inflammatory treatment [4-7].

In addition to medical therapy, there are two widely utilized surgical procedures, cyclosporine suprachoroidal implants (CSI) and pars plana vitrectomy (PPV), that are routinely performed to treat horses with ERU [8-14]. Implantation of a CSI has been proven to be an effective means of controlling uveitis in horses responsive to prior medical therapy $[3,8,13,15]$. However, because their legal importation into Europe is restricted to academic institutions for specific use in ongoing research, the use of CSI is severely limited on this continent. A more commonly performed surgery in Europe (especially Germany) is the PPV $[9,10,14,16]$. Initially, PPV was utilized to treat all forms of ERU, but recently published data suggests that it is most effective in horses with confirmed leptospiral etiology [14].

Two recent studies demonstrated the relative inability of medical therapy to adequately control and prevent long-term complications and blindness in a large proportion of horses evaluated, highlighting the importance of additional treatment modalities [17, 18]. Intravitreal injections with triamcinolone acetonide or rapamycin have been successfully utilized in the management of recurrent uveitis in humans, as well as in small groups of horses [19-23]. However, the rate of complications and lack of long-term control of ERU, has limited their use in equine ophthalmology. Gentamicin $(0.2-0.4 \mathrm{mg} / \mathrm{ml})$, a bactericidal aminoglycoside antibiotic, has been routinely added to the PPV irrigation solution since the surgery's introduction in the early 1990s [9-11, 24]. This led to speculation that low-dose intravitreal gentamicin ( $4 \mathrm{mg}$ ) injections (IVGI) alone could serve as an alternative treatment for ERU, and initial results were presented by Pinard, et al. in 2005 [25]. Despite widespread anecdotal use, there are no published studies evaluating the efficacy of this treatment or establishing the risk of complications following IVGI.

The purpose of this prospective study was to describe the intravitreal gentamicin injection technique, to identify any peri-injection (within $24 \mathrm{~h}$ ) and/or post-injection (30 to 780 days follow-up) complications associated with the IVGI and to evaluate the clinical outcome in horses with ERU, following a single $4 \mathrm{mg}$ IVGI. Additionally, aqueous humor (AH) and serum (S) samples were evaluated for the presence of leptospiral antibody titers ( $\mathrm{S}$ and
$\mathrm{AH})$ and leptospiral DNA (AH) and their effect on the treatment outcome.

\section{Results \\ Horses}

A total of 86 horses with a mean follow-up period of $165.9 \pm 190.3$ days (range: 1 to 780 days) were included in the present study. The mean age was $11.6 \pm 5.5$ years (range: 2 to 28 years). Gender, breed and coat color distribution can be found in Table 1. Twenty-nine horses were treated bilaterally, resulting in one eye being randomly selected for evaluation.

Fifty-nine of the 86 eyes had a minimum follow-up period of 30 days (range: 30 to 780 days) and comprised the group undergoing statistical evaluation of post-injection complications and clinical treatment outcome. Fifty-two of 59 eyes (88.1\%) were controlled (non-recurrence/persistence, independent of complications) after the IVGI, and despite the discontinuation of topical and medical therapy. Overall, $5 / 59$ eyes $(8.5 \%)$ presented with recurrent and $2 / 59$ eyes (3.4\%) presented with persistent inflammation during follow-up examination. The follow-up data and corresponding results of positive outcome are listed in Table 2. Category distributions are listed in Fig. 1, Tables 3 and 4.

\section{Leptospira status}

Aqueous humor was obtained from 79/86 (91.9\%) eyes and serum from 80/86 (93\%) horses. Table 5 shows the calculated c-values for each individual Leptospira serovar and the combined results are documented in Table 6 . Leptospira PCR was performed on 79 eyes, 23 of which were positive 23/79 (29.1\%). Based on our inclusion criteria and calculation of c-values for each eye 50/79 eyes $(63.3 \%)$ were classified as Leptospira negative, 13/79 eyes (16.5\%) were classified as Leptospira suspicious and the remaining $16 / 79$ eyes (20.3\%) were classified as Leptospira positive.

\section{Peri-injection complications}

Subconjunctival and intracameral hemorrhage (due to the aqueous paracentesis) were seen in 26/86 (30.2\%) and $4 / 86(4.7 \%)$ of the eyes, respectively, but were completely resolved within 5 days.

\section{Post-injection complications}

Fifty-nine of 86 eyes had a minimum follow-up period of 30 days (30-780 days) and were evaluated for the presence of post-injection complications. Cataract formation/maturation was observed in 5/59 (8.5\%) eyes, and retinal degeneration was seen in $3 / 59$ eyes $(5.1 \%)$. Four of the five cataracts that developed post-injection were identified in horses that received gentamicin with preservatives. Cataract progression/maturation occurred within 
Table 1 Gender, breed and coat color distribution of the horses $(n=86)$ that had undergone IVGI between January 2013 - June 2016

\begin{tabular}{llll}
\hline Gender $\mathbf{n = 8 6}$ & Geldings & 49 & $(57 \%)$ \\
& Mares & 31 & $(36 \%)$ \\
\hline Breed $\mathbf{n}=\mathbf{8 6}$ & Stallions & 6 & $(7 \%)$ \\
\hline & Warmblood & 38 & $(44.2 \%)$ \\
& Quarter Horse; Paint Horse & 9 & $(10.5 \%)$ \\
& Icelandic Horse & 6 & $(7.0 \%)$ \\
& Pony & 6 & $(7.0 \%)$ \\
& Heavy Warmblood & 5 & $(5.8 \%)$ \\
& Standardbred Trotter & 5 & $(5.8 \%)$ \\
& Haflinger & 5 & $(5.8 \%)$ \\
& Appaloosa & 4 & $(4.7 \%)$ \\
& Spanish & 3 & $(3.5 \%)$ \\
& Knabstrupper & 3 & $(3.5 \%)$ \\
& Thoroughbred & 2 & $(2.3 \%)$ \\
\hline Coat Color Distribution & Bay & 36 & $(41.9 \%)$ \\
& Chestnut & 16 & $(18.9 \%)$ \\
& Gray & 11 & $(12.8 \%)$ \\
& Leopard-patterned & 11 & $(12.8 \%)$ \\
& Black & 7 & $(8.1 \%)$ \\
& Dun & 5 & $(5.8 \%)$ \\
\hline
\end{tabular}

one week $(1 / 5,20 \%)$, within one year $(3 / 5,60 \%)$, and later than one year post-IVGI $(1 / 5,20 \%)$. All eyes, that developed mature cataracts, presented with cataracts of different stages before IVGI (Fig. 2). Retinal degeneration, not associated with obvious visual deficits (as assessed via menace response), was identified in 3/59 (5.1\%) eyes (Fig. 3), and was consistently identified as a horizontal, geographic area (between one and three disc diameters in size) of diffuse tapetal hyperreflectivity superior to the optic nerve head. This complication was identified in a single eye at each of the following time points: Within 30 days, between 30 and 60 days, and between 90 and 122 days following IVGI, respectively. None of these eyes showed signs of retinal degeneration prior to IVGI.

\section{Statistical evaluation of factors influencing treatment outcomes and complication rates}

Variables with a significant effect on treatment outcome or on the development of long-term complications, are presented in Table 7. A significant correlation was identified between the Appaloosa breed and recurrence of inflammation $(P<0.001)$. In each of these horses, uveitis remained controlled in the early stages of follow-up. However, over time, aqueous flare was detectable in all three eyes. Leopard-patterned horses were more likely to develop recurrent inflammation than horses with other coat colors $(P=0.049)$. None of the eyes, that developed retinal degeneration, had detectable aqueous flare pre-IVGI $(P=0.046)$. The presence of subconjunctival or intracameral hemorrhage post-IVGI did not have a significant influence on either the control of the uveitis, or the development of long term-complications. Neither the clinical diagnosis, nor the additional categories utilized to subjectively grade equine uveitis in the present study had any influence on the control of the uveitis or the development of post-injection complications. The Leptospira antibody status of the eye (positive, suspicious, or negative C-value) and aqueous humor Leptospira PCR results did not have a significant influence on the development of long-term complications. There was a significant influence on the development of persistent inflammation in one eye with multiple positive $\mathrm{C}$-values $\geq 4$ ( $\mathrm{C}$-value of 8 for $L$. pomona and C-Value of 4 for $L$. grippotyphosa) $(P=0.015)$, multiple aqueous humor titers $\geq 1: 400$ (aqueous humor titer for L. Pomona 1:800 and for L. grippotyphosa 1:1600) $(P=0.013)$ and one positive serum titer $\geq 1: 400$ (serum titer for L. grippotyphosa 1:400) $(P=0.047)$. Although not significant, $4 / 5 \quad(80 \%)$ mature cataracts developed following IVGI injection with gentamicin containing preservatives (Genta100).

\section{Discussion}

Many horses with ERU require additional treatment modalities in addition to medical therapy. Both the PPV and CSI placement are commonly performed in Europe and the USA, respectively $[8,15,16,26]$. Although CSI placement can effectively suppress intraocular

Table 2 Follow-up periods and clinical outcomes post-intravitreal gentamicin injections

\begin{tabular}{lllll}
\hline Minimum follow-up period & $\begin{array}{l}\text { Controlled ERU } \\
\text { (no recurrent or } \\
\text { persistent inflammation, } \\
\text { independent of } \\
\text { complications) }\end{array}$ & $\begin{array}{l}\text { Average follow-up } \\
\text { period (days) }\end{array}$ & $\begin{array}{l}\text { Standard deviation } \\
( \pm \text { days) }\end{array}$ \\
\hline $\mathbf{3 0}$ days 59/86 (68.6\%) eyes & $\begin{array}{l}52 / 59 \text { eyes } 88.1 \% \\
\text { Range (days) }\end{array}$ \\
$\mathbf{3}$ month 43/86 (50.0\%) eyes & $36 / 43$ eyes 83.7\% & 238 & 190 & $30-780$ \\
$\mathbf{5}$ month 34/86 (39.5\%) eyes & $27 / 34$ eyes 79.4\% & 313 & 175 & 164 \\
$\mathbf{7}$ month 24/86 (27.9\%) eyes & $20 / 24$ 83.3\% & 359 & 170 & $153-780$ \\
$\mathbf{1}$ year 12/86 (14.0\%) eyes & $9 / 12$ eyes 75\% & 407 & 137 & $365-780$ \\
\hline
\end{tabular}




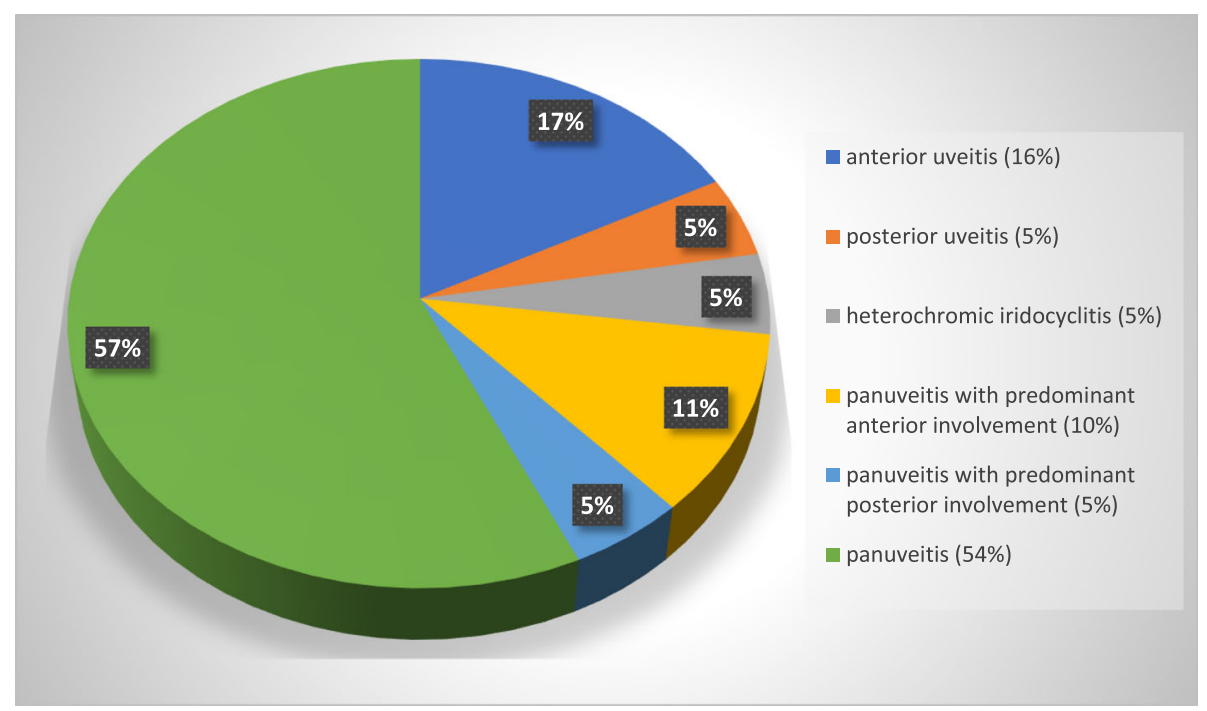

Fig. 1 Distribution of clinical signs of uveitis

inflammation and prevent recurrent inflammatory bouts for several years, they are not readily available in Europe due to legal restrictions governing their importation. Additionally, there are several instances where PPV (e.g., radial retinal detachments, late immature to mature cataracts present) or CSI (e.g., uncontrollable inflammation despite appropriate medical therapy) are contraindicated. Thus, additional or alternative treatment options, such as IVGI, may enable us to better control this highly debilitating disease. attractive.

Aqueous paracentesis and IVGI can be performed during the same sedation, using minimal regional and topical anesthesia; thus, negating the need for general anesthesia. Ultimately, only those horses not being controlled with IVGI require additional surgical intervention. This has dramatically reduced the number of horses requiring surgical intervention to control ERU in our clinic population. However, if an eye fails to be controlled with IVGI, the Leptopsira status, previously obtained via aqueous paracentesis, can then be used to choose the most appropriate surgical intervention, e.g., a PPV or CSI.

Serum Leptospira antibodies are able to effectively cross the blood-ocular barriers in the presence of uveitis, therefore only local antibody production at the site of the inflamed tissue is a true indicator for a Leptospira-induced mechanism of action. Individual aqueous humor or serum antibody titers are unreliable predictors of involvement [27]. In order to accurately identify Leptospira's role in the pathogenesis of equine uveitis it is important to calculate the c-value (i.e., the ratio between aqueous humor and serum antibody titers) [14].

The main goals in treating ERU are the reduction of ocular inflammation, the reduction or elimination of pain or discomfort, and the preservation of vision $[3$, 17]. According to a recent study by Gerding and Gilger, nearly half of the eyes affected with uveitis became blind, regardless of the therapy implemented [17]. In a study from Germany, evaluating the post-operative results following PPV for the treatment of ERU, 17/43 (39.5\%) of the eyes had improved vision, $14 / 43(32.6 \%)$ of the eyes demonstrated reduced vision, and $12 / 43(27.9 \%)$ of the eyes were blind following the surgery [12]. Long-term results following implantation of a CSI revealed that 119/ $151(78.8 \%)$ of the eyes remained visual [13]. Although the results of the present study (Table 4) are not directly comparable with the previous reports, the vision status of the eyes in this study remained unchanged following IVGI in $71.2 \%(42 / 59)$ eyes, were improved in $18.6 \%$ (11/59) eyes, and deteriorated in $10.2 \%$ (6/59) eyes. Each eye that developed mature cataracts post-IVGI had some degree of immature cataract maturation prior to IVGI (Fig. 2). Despite

Table 3 Characteristics of uveitis

\begin{tabular}{|c|c|c|c|c|c|}
\hline acute/chronic $n=86$ eyes & $\begin{array}{l}\text { acute } \\
4(4.7 \%)\end{array}$ & & $\begin{array}{l}\text { chronic } \\
25(29.1 \%)\end{array}$ & & $\begin{array}{l}\text { chronic-acute } \\
57(66.3 \%)\end{array}$ \\
\hline $\begin{array}{l}\text { recurrent/persistent } \\
n=86 \text { eyes }\end{array}$ & & $\begin{array}{l}\text { recurrent } \\
36(41.9 \%)\end{array}$ & & $\begin{array}{l}\text { persistent } \\
50(58.1 \%)\end{array}$ & \\
\hline $\begin{array}{l}\text { presence of aqueous flare } \\
n=86 \text { eyes }\end{array}$ & $\begin{array}{l}0 \text { (no flare) } \\
42(48.8 \%)\end{array}$ & $\begin{array}{l}1 \text { (faint flare) } \\
20(23.3 \%)\end{array}$ & $\begin{array}{l}2 \text { (moderate flare) } \\
13(15.1 \%)\end{array}$ & $\begin{array}{l}\mathbf{3} \text { (severe flare) } \\
3(3.5 \%)\end{array}$ & $\begin{array}{l}4 \text { (blood or fibrin in } \\
\text { anterior chamber) } 8 \text { (9.3\%) }\end{array}$ \\
\hline
\end{tabular}


Table 4 Subjective visual assessment pre- and post-IVGI and the subsequent change, or lack thereof, in the individual eyes evaluated

\begin{tabular}{llll}
\hline Pre-IVGI $\mathbf{n}=\mathbf{8 6}$ eyes & GOOD & REDUCED & POOR \\
& $42(48.8 \%)$ & $20(23.3 \%)$ & $24(27.9 \%)$ \\
Post-IVGI $\mathbf{n}=\mathbf{5 9}$ eyes & GOOD & REDUCED & POOR \\
& $38(64.4 \%)$ & $8(13.6 \%)$ & $13(22.0 \%)$ \\
Change in status following IVGI $\mathbf{n}=\mathbf{5 9}$ eyes & UNCHANGED & IMPROVED* & DETERIORATED** \\
& $42(71.2 \%)$ & $11(18.6 \%)$ & $6(10.2 \%)$ \\
\hline
\end{tabular}

*from a POOR to a REDUCED or GOOD vision status or from a REDUCED to a GOOD vision status)**from a GOOD to REDUCED or POOR or from REDUCED to POOR vision status due to cataract formation or phthisis bulbi

this, the degree of cataract maturation prior to IVGI cannot be reliably utilized to predict the likelihood of cataract progression/maturation following IVGI. None of the horses that developed post-IVGI retinal degeneration demonstrated any subjective behavioral changes (e.g., head carriage abnormalities (head tilt), spooky or erratic behavior, hesitant to move or navigate obstacles in a known environment) suggesting that vision was compromised, nor did they not show detectable clinical signs of vision loss (menace response). However, we cannot conclude that vision was not compromised. Additional functional testing methods, such as pre-IVGI and post-IVGI electroretinography (ERG) would provide more objective and meaningful results pertaining to retinal function, and should be considered for future studies. Although none of the three eyes that developed retinal degeneration had flare at the time of IVGI, the clinical disease progression in each of these horses differed significantly enough to prevent us from drawing a reliable conclusion as to why this complication occurred. We cannot exclude that eyes presenting with a mature cataract did not develop retinal degeneration. The risks of potential cataract maturation and retinal degeneration cannot be ignored, and must be discussed in detail with the owner when discussing treatment options. There are many factors that will ultimately determine if an IVGI is indicated, thus, it is important to provide an accurate risk-benefit analysis for each individual horse. Further investigation into the post-injection development of retinal degeneration is warranted. Ongoing efforts include functional testing via ERG and posterior segment evaluation via optical coherence tomography (OCT). The fact that there was a significant influence on the development of persistent inflammation in one eye with multiple positive $\mathrm{C}$-values $\geq 4$ of different Leptospira titers, multiple aqueous humor Leptospira titers $\geq 1: 400$ of different serovars and one positive serum Leptospira titer $\geq 1: 400$ warrants further investigation, but caution must be taken when interpreting this data, as only a single eye was affected. The complication rates associated with IVGI (88.1\% non-recurrence/non-persistence rate, $8.5 \%$ cataract progression/maturation, and $5.1 \%$ retinal degeneration) are comparable to published results following CSI placement (46\% non-recurrence rate, $16 \%$ cataract progression/formation and $16 \%$ retinal degeneration) and PPV (73.6-100\% non-recurrence rate, $38.2-44.2 \%$ cataract progression/formation, and 9.3\% retinal degeneration) [9-14].

Presently, the mechanism of action of gentamicin on the disease process in ERU and other types or stages of equine uveitis remains enigmatic. Positive suppression of inflammation, which can be observed as early as 24-48 $h$ post-IVGI, was achieved in various types and stages of equine uveitis despite the Leptospira status of the eye, in the present study. Therefore, we speculate that rather than having a direct bactericidal effect on putative bacterial organisms, gentamicin instead influences or interferes with the immune-mediated processes intrinsic to ERU. Although purely speculative, the underlying mechanism of action of gentamicin may block or suppress the activation of specific T-cell lines; cells that are known to play a significant role in autoimmune uveitis [28]. Further research into gentamicin's mechanism of action following intravitreal injection is necessary.

Limitations of the present study are the short follow-up periods utilized for evaluation following IVGI. Despite the short follow-up duration, a 30-day minimum follow-up period was selected in order to capture the immediate effects of IVGI and to ensure that all complications seen associated with this technique were observed and recorded. Had we selected a longer minimum follow-up period, $1 / 3(33.3 \%)$ of the eyes that

Table 5 Single c-value results for individual Leptospira serovars

\begin{tabular}{|c|c|c|c|c|c|c|c|c|c|}
\hline \multirow[t]{2}{*}{ Result } & \multicolumn{9}{|c|}{ C-values for individual Leptospira (L.) serovars } \\
\hline & $\begin{array}{l}\text { sejroe } \\
(n=63)\end{array}$ & $\begin{array}{l}\text { saxkoebing } \\
(\mathrm{n}=63)\end{array}$ & $\begin{array}{l}\text { canicola } \\
(n=63)\end{array}$ & $\begin{array}{l}\text { autum-nalis } \\
(n=79)\end{array}$ & $\begin{array}{l}\text { grippo-typhosa } \\
(n=79)\end{array}$ & $\begin{array}{l}\text { pomona } \\
(n=79)\end{array}$ & $\begin{array}{l}\text { australis } \\
(\mathrm{n}=79)\end{array}$ & $\begin{array}{l}\text { ictero-haemorrhagiae/ } \\
\text { copenhageni }(n=79)\end{array}$ & $\begin{array}{l}\text { bratislava } \\
(n=79)\end{array}$ \\
\hline Posititive (+) & 0 & 0 & 0 & $1(1.3 \%)$ & $15(19.0 \%)$ & $4(5.1 \%)$ & $1(1.3 \%)$ & $1(1.3 \%)$ & $1(1.3 \%)$ \\
\hline Negative (-) & $63(100 \%)$ & $62(98.4 \%)$ & $63(100 \%)$ & 74 (93.7\%) & $54(68.4 \%)$ & $69(87.3 \%)$ & 75 (95.0\%) & 77 (95.0\%) & $75(95.0 \%)$ \\
\hline Suspicious (?) & 0 & $1(1.6 \%)$ & 0 & $4(5.1 \%)$ & $10(12.7 \%)$ & $6(7.6 \%)$ & $3(3.8 \%)$ & $1(1.3 \%)$ & $4(5.1 \%)$ \\
\hline
\end{tabular}


Table 6 Combined serum and aqueous humor Leptospira titer results and the corresponding Leptospira c-value results

\begin{tabular}{|c|c|c|c|c|c|}
\hline Titer & $\begin{array}{l}\text { negative } \\
\text { titer(s) }\end{array}$ & $\begin{array}{l}\text { SINGLE SEROVAR } \\
\text { positive titer }(<1: 400)\end{array}$ & $\begin{array}{l}\text { MULTIPLE SEROVARS } \\
\text { positive titers }(1: 100-1: 400)\end{array}$ & $\begin{array}{l}\text { SINGLE SEROVAR } \\
\text { positive titer }(>1: 400)\end{array}$ & $\begin{array}{l}\text { MULTIPLE SEROVARS } \\
\text { positive titers }(>1: 400)\end{array}$ \\
\hline $\begin{array}{l}\text { Serum } \\
(n=80)\end{array}$ & 41 (51.3\%) & $20(25.0 \%)$ & $10(12.5 \%)$ & $6(7.5 \%)$ & 3 (3.8\%) \\
\hline $\begin{array}{l}\text { Aqueous humor } \\
(n=79)\end{array}$ & 49 (62.0\%) & 11 (13.9\%) & 1 (1.3\%) & $13(16.5 \%)$ & 5 (6.3\%) \\
\hline $\begin{array}{l}\text { C-value } \\
\text { (different serovars) }\end{array}$ & $\begin{array}{l}\text { NO positive } \\
\text { c-value }\end{array}$ & $\begin{array}{l}\text { SINGLE positive } \\
\text { c-value (less than 4) }\end{array}$ & $\begin{array}{l}\text { MULTIPLE positive } \\
\text { c-values (less than 4) }\end{array}$ & $\begin{array}{l}\text { SINGLE positive } \\
\text { c-value (greater than 4) }\end{array}$ & $\begin{array}{l}\text { MULTIPLE positive } \\
\text { c-values (greater than 4) }\end{array}$ \\
\hline $\begin{array}{l}\text { C-value } \\
(\mathrm{n}=79)\end{array}$ & $50(63.3 \%)$ & 12 (15.2\%) & $1(1.3 \%)$ & 11 (13.9\%) & $5(6.3 \%)$ \\
\hline
\end{tabular}
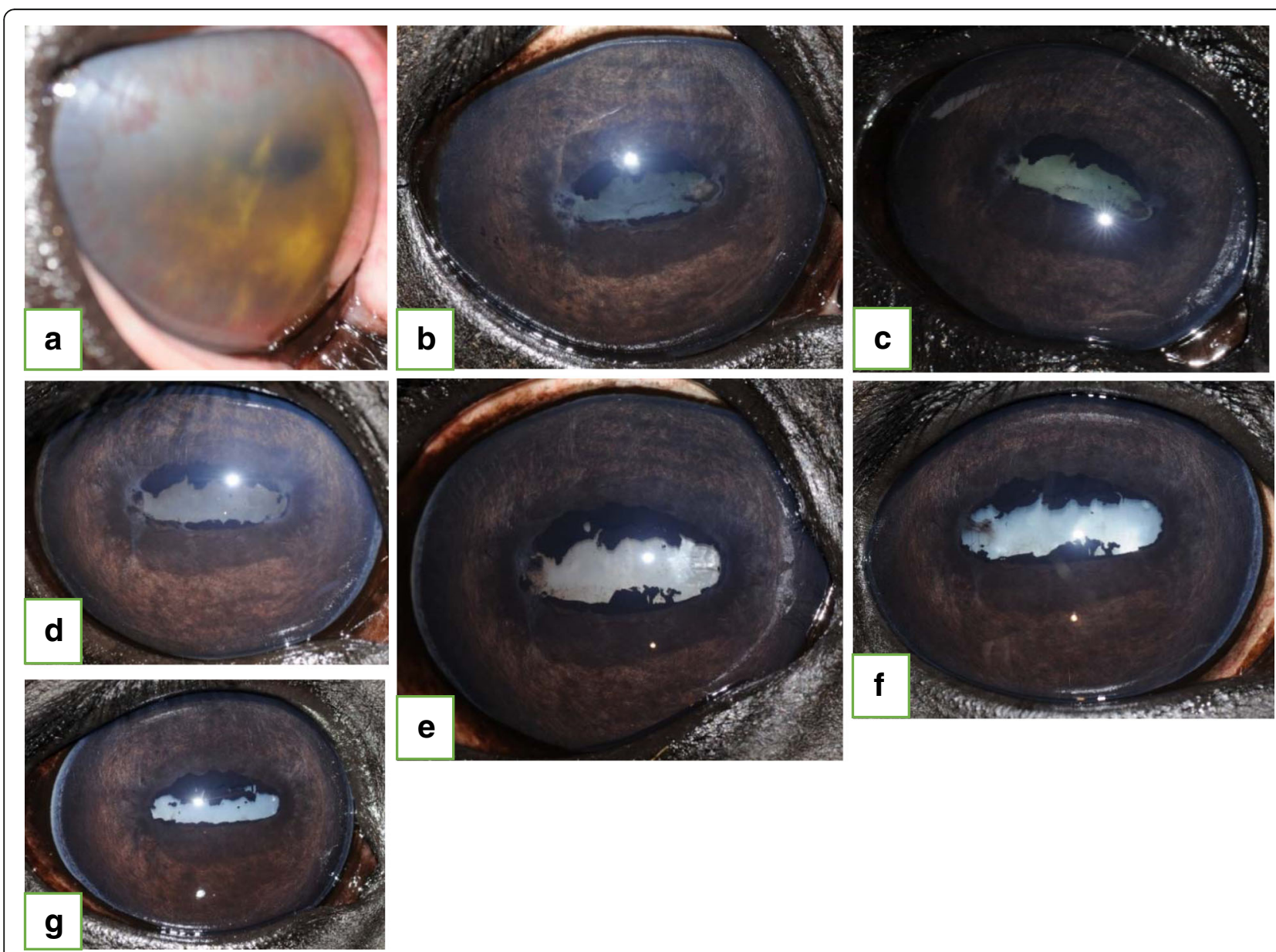

Fig. 2 Nine-year old warmblood gelding presented with chronic-acute, persistent panuveitis of the right eye (OD). Negative c-value for Leptospira. a. Initial presentation: Blepharospasm, epiphora, diffuse corneal edema, $360^{\circ}$ corneal neovascularization, $+4 / 4$ flare, fibrin in anterior chamber and miosis were present. The posterior aspect of the eye could not be visualized. Inflammation was controlled with medical therapy. b. One-hundred-fifteen days post-initial presentation: Two additional bouts of inflammation since initial presentation. Both intravitreal gentamicin injection (IVGI) and aqueocentesis were performed. Immature cataract and posterior synechia were present at the time of IVGI OD. c. Seven days post-IVGI OD: Immature cataract. d. Sixty days post-IVGI OD: Medical treatment was discontinued 39 days prior to this examination. No signs of active inflammation could be identified. e. One-hundred-thirteen days post IVGI OD: Mature cataract (cataract maturation). No signs of active inflammation. f. Three-hundred-twenty-seven days post-IVGI OD: Uveitis remains controlled without medical treatment. g. Six-hundred-two days post-IVGI OD: No recurrent bouts of inflammation since IVGI 


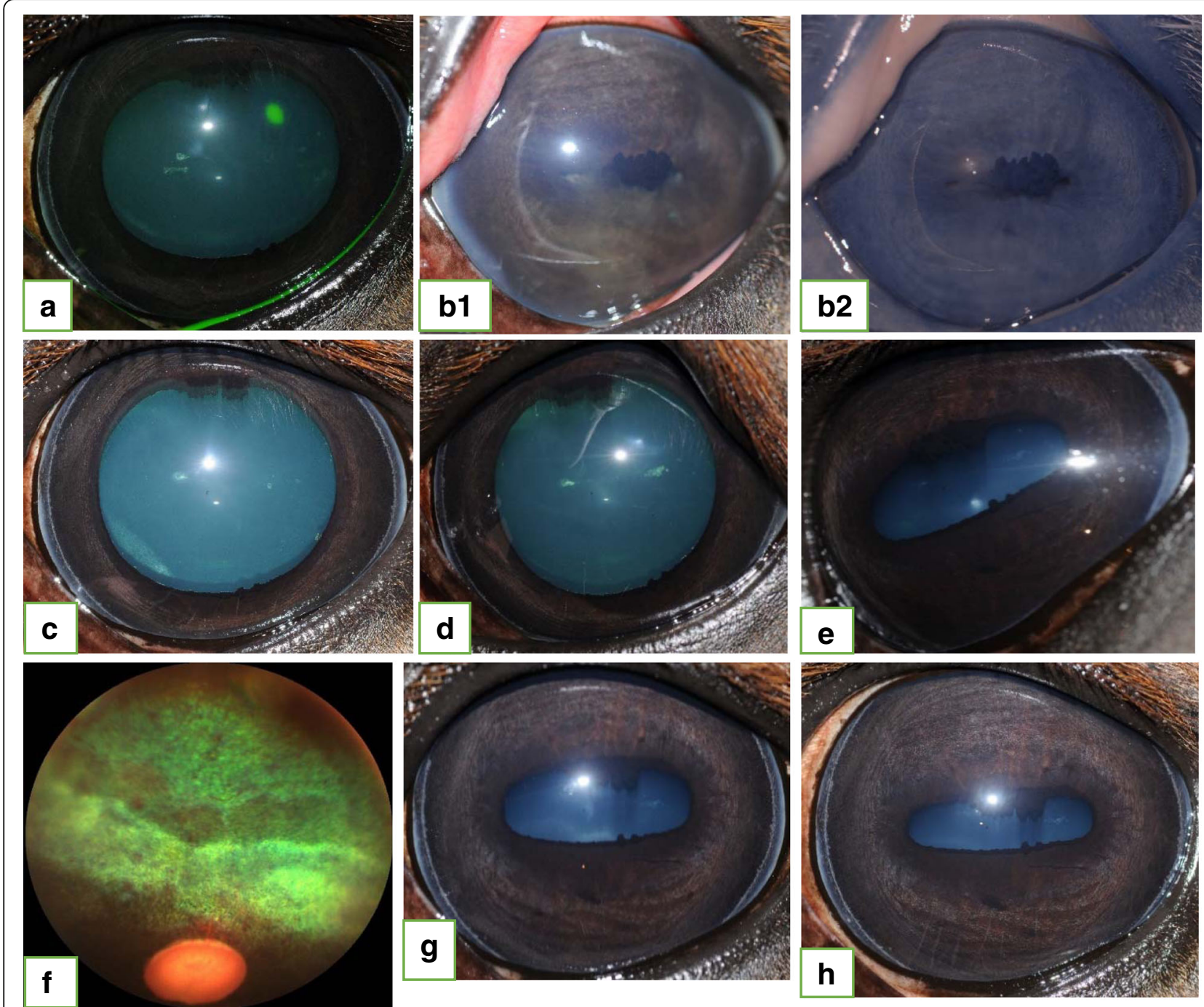

Fig. 3 Eight-year old warmblood mare that presented for chronic-acute, recurrent anterior uveitis in the left eye (OS). Negative c-value for Leptospira. a. Initial presentation: Two days following the onset of an acute bout of inflammation. Topical and systemic therapy were initiated by the referring veterinarian, when ocular signs were first identified. Inflammation was controlled via medical therapy. b1. Seven months after initial presentation: Active uveitis OS; + 4/4 flare, fibrin and complete miosis were present. b2. Infrared picture of OS at the same examination as in B1. c. Uveitis was controlled within 5 days of initiating medical therapy. d. Recurrent acute inflammation: 14 months later. Intravitreal gentamicin injection (IVGI) and aqueocentesis were performed. e. Ninety-eight days post-IVGI OS: Uveitis has remained controlled following IVGI. A focal area of tapetal hyperreflectivity identified during indirect ophthalmoscopy of the fundus. f. Fundus image of the lesion described in e. Retinal degeneration developed between the 30- and 98- day recheck examination. Subjective vision status unchanged from pre-IVGl. g. Two-hundred-seventy days post-IVGI OS: Uveitis controlled. Retinal degeneration remains static. h. Three-hundred-eighty-five days post-IVGI OS: Uveitis remains controlled. Retinal degeneration remains static

developed retinal degeneration and $1 / 5(20 \%)$ of those, where cataract progression was observed would have not been included in our results, thus introducing a false positive bias into our complication rates. One cataract, that would not have been included otherwise, developed when using preservative-free gentamicin. Thus, setting the minimum-follow-up period at a time point further out from the IVGI (e.g., 5 months) would have prevented inclusion of those complications from our results, as a result, an incorrect conclusion would have been drawn that no cataract progression/maturation occurred when utilizing PFG for the IVGI. Future studies evaluating the clinical outcome and the presence or development of long-term complications over multiple years are necessary and are currently underway.

The present study reports control of ERU in $88.1 \%$ (non-recurrence/non-persistence rate) in the absence of medical treatment of the eyes with a minimum follow-up period of 30 days. These results support the 
Table 7 Individual variables with positive correlation to treatment outcome or the development of post-injection complications

\begin{tabular}{lll}
\hline Variable & Treatment Outcome & Post-Injection Complications \\
\hline Breed & Appaloosas: more recurrent inflammation than other breeds & NC \\
Coat color & $\begin{array}{l}\text { Leopard patterned: more recurrent inflammation than other } \\
\text { coat colours }\end{array}$ & NC \\
Flare pre-IVGI & NC & NO flare: increased risk of retinal degeneration \\
Leptospira status of the eye & $\begin{array}{l}\text { Multiple positive C-values ( } \geq 4) \text { for multiple individual } \\
\text { serovars: increased incidence of persistent inflammation }\end{array}$ & NC \\
Aqeuous humor titer in total & $\begin{array}{l}\text { Multiple positive individual aqueous humor titers for Leptospira } \\
(\geq 1: 400) \text { : increased incidence of persistent inflammation }\end{array}$ & NC \\
Single serum titer & $\begin{array}{l}\text { One positive serum titer for Leptospira }(\geq 1: 400) \text { : increased } \\
\text { incidence of persistent inflammation }\end{array}$ & NC \\
\hline
\end{tabular}

Abbreviations: NC no correlation

anecdotal findings reported by Pinard in 2005 with a positive outcome of $94.4 \%$, and those reported by Kleinpeter in 2014 showing a positive outcome in $93.3 \%$ (follow-up: 2-96 month) [25, 29]. In the latter study, 11/ $60(18.3 \%)$ eyes became blind due to cataract formation following IVGI [25]. When comparing this result to the first 34 eyes in the present study that were treated with gentamicin containing preservatives, similar rates of cataract formation or maturation (4/34 (11.8\%) eyes) were observed [25]. Because cataract maturation was observed most often in eyes with moderate pre-existing cataracts, we speculated that the preservatives in Genta 100 may have contributed to the accelerated cataract maturation in these cases. In order to minimize this risk, we switched to PFG solution after making this observation. After switching to PFG, only a single cataract progressed from immature to mature (1/52 eyes, $1.9 \%)$. Although the exact risk of cataract maturation associated with PFG IVGI is unknown, it appears that utilization of a PFG solution may help to minimize the actual risk of developing this blinding complication post-IVGI.

\section{Conclusion}

With less than $9 \%$ of the horses in the present study developing recurrent or persistent inflammation, less than $9 \%$ with cataract maturation and less than $6 \%$ with retinal degeneration, IVGI was associated with a lower level of complications compared with medical therapy $[3,17,18]$ and other commonly implemented surgical treatment options for ERU (CSI placement and PPV) [10-13]. The ability of low-dose IVGI with $4 \mathrm{mg}$ gentamicin (especially PFG) to suppress active inflammation in various types and stages of equine uveitis in the present study despite the Leptospira status of the eye, adds another treatment option in the management of a severely debilitating and vision threatening disease.

\section{Methods}

Case selection

Complete initial and all follow-up ophthalmic examinations were performed by a board-certified veterinary ophthalmologist (RJM) between January 2013 through June 2016 in south-east Germany. Horses presenting with signs of active or chronic uveitis and a history of recurrences were included in the study. Signs associated with recurrent or persistent uveitis included, but were not limited to, blepharospasm, epiphora, keratic precipitates (KP), aqueous flare, fibrin in the anterior chamber (AC), hyphema, miosis, corpora nigra atrophy or degeneration, iris hyper- or depigmentation, equatorial vesicular cataracts, posterior lens capsule adhesions or opacifications, vitreous body opacifications, and retinal detachment. Horses with uveitis resulting from putative trauma, secondary to infectious corneal diseases, or following intraocular surgery, were excluded.

Owners were educated on the various medical and surgical (i.e., PPV, CSI, and intravitreal injections) treatment options, and risks associated with each option. Client consent to perform the IVGI was obtained following an in-depth discussion of potential complications including failure of the selected treatment option to control the disease, resulting in persistent/ recurrent inflammation with progression of ocular signs, and potential cataract maturation or development and retinal degeneration or detachment.

\section{Examination}

Complete ophthalmic examinations were performed on initial presentation, and on each subsequent follow-up examination, and consisted of a subjective clinical vision assessment (menace response) and neuro-ophthalmic evaluation (dazzle, and pupillary light reflexes (PLR)), slit lamp bio microscopy (Kowa SL-15), ${ }^{1}$ indirect ophthalmoscopy (Keeler Vantage), ${ }^{2}$ rebound tonometry (TonoVet), ${ }^{3}$ external ocular fluorescein dye 
application (Fluoreszein SE Thilo), ${ }^{4}$ and color (Nikon D300s) $)^{5}$ and infrared (Nikon D200) ${ }^{5}$ (sensor conversion $)^{6}$ digital imaging. Aqueous flare was graded as follows: 0 (none), 1 (faint), 2 (moderate), 3 (severe) or 4 (blood or fibrin present in the anterior chamber) [30]. Fundus images (Kowa Genesis or ClearView) ${ }^{1,7}$ were obtained in horses with posterior segment abnormalities, when possible.

\section{Categorization of uveitis}

For statistical purposes, each case was diagnosed with one of the following: 1. Panuveitis (global uveal inflammation with equal distribution of clinical signs between the anterior and posterior segment); (Figs. 2 and 4); 2. Panuveitis with predominant anterior segment involvement; 3. Panuveitis with predominant posterior segment involvement; 4. Anterior uveitis; (Fig. 3); 5. Posterior uveitis; and 6. Heterochromic iridocyclitis with secondary keratitis (HIK), a recently described, specific form of idiopathic anterior uveitis (iridocyclitis) and corneal endothelial inflammation associated with iris pigment dispersion and retro-corneal fibrous membrane formation $[2,3,8,31]$.

Each case was further categorized as "acute" (active inflammation without overt signs of chronicity), "chronic" (signs of chronicity but no signs of active inflammation) or "acute/chronic" (acute onset of inflammation associated with chronic inflammation). "Recurrent uveitis" was diagnosed when at least 2 episodes of recurrent inflammation occurred despite appropriate medical therapy leading to a period of quiescence following cessation of medical therapy. "Persistent inflammation" was diagnosed when an initial or recurrent bout of inflammation remained actively inflamed for a minimum of four weeks despite aggressive and appropriate medical or surgical therapy (Fig. 4).

The subjective vision status prior to, and following, IVGI was graded as "good" (positive menace, dazzle, direct and indirect PLR, with no evidence of obvious visual field impairment due to corneal edema, hyphema, hypopyon, fibrin in the anterior chamber, miosis, synechia, lens opacities/cataracts, vitreal degeneration, fundus abnormalities), "reduced" (positive menace, dazzle, direct and indirect PLR with some evidence of visual field impairment due to the abnormalities listed above) and "poor" (negative or positive menace, dazzle and direct and indirect PLR with obvious evidence of visual field impairment (late immature to mature cataracts), retinal degeneration/ detachment, or phthisis bulbi).
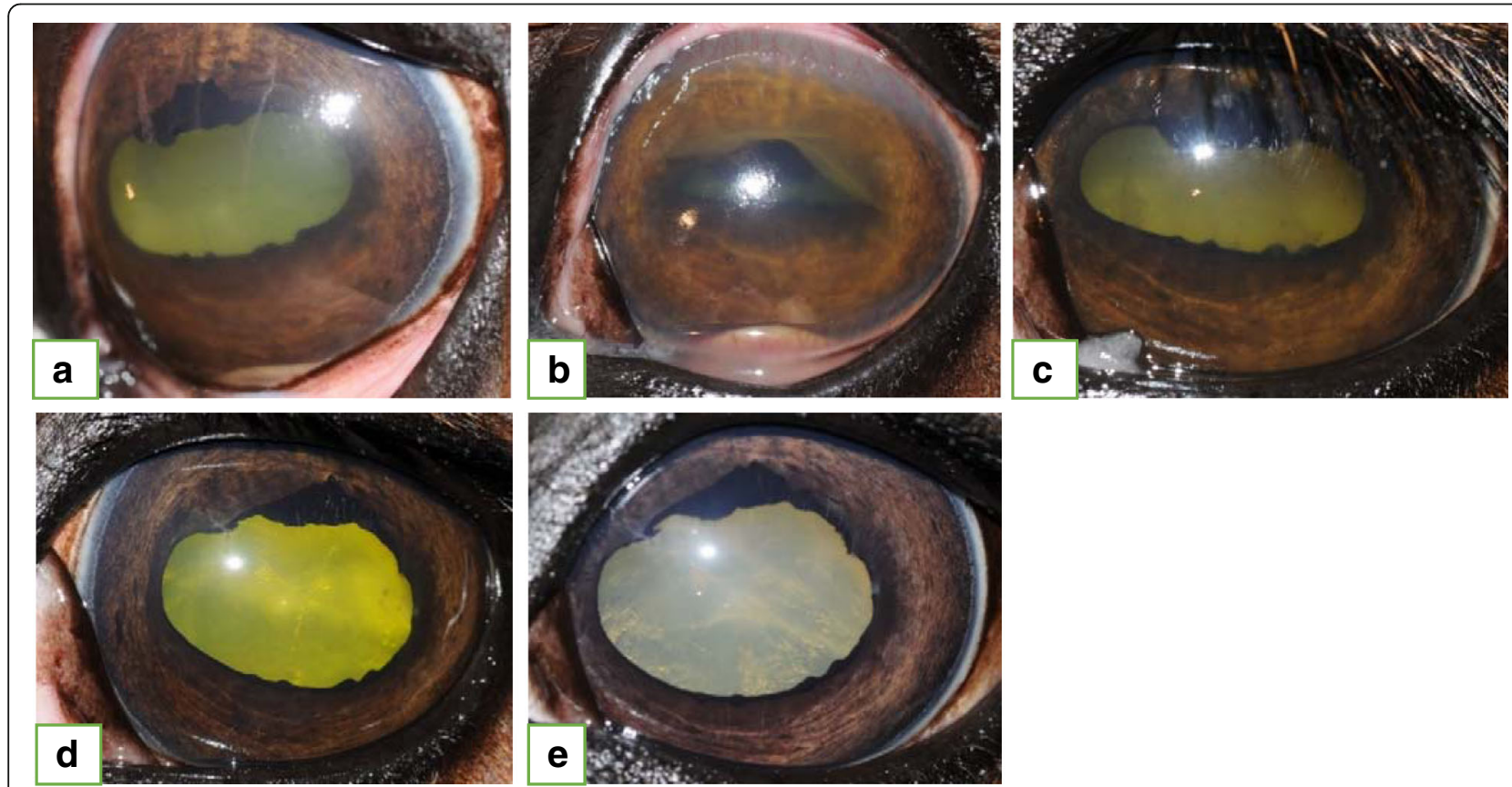

Fig. 4 Twelve-year old warmblood mare that presented for a chronic-acute persistent panuveitis of the left eye (OS). Negative c-value for Leptospira. a. Initial presentation: Diffuse corneal edema, keratic precipitates, $+2 / 4$ flare, fibrin, vitreal degeneration and retinal folds were present. Medical treatment was started (prednisolone acetate q $4-6 \mathrm{~h}$, atropine $\mathrm{q} 8 \mathrm{~h}$ and flunixine meglumine $1.1 \mathrm{mg} / \mathrm{kg}$ twice daily). b. Ten days post initial presentation: The clinical signs worsened in the face of aggressive medical treatment. Intravitreal gentamicin injection and aqueocentesis were performed OS. c. Four days post-IVGI OS: Improvement of clinical signs can be readily appreciated. d. Twenty days post-IVGI OS: No flare present. e. Forty-nine days post-IVGI OS: Uveitis remains controlled without medications. The mare was euthanized due to complications associated with cervical spinal fracture 2 months after IVGI 


\section{Sedation, intravitreal gentamicin injection and aqueous paracentesis}

A general physical examination including auscultation and body temperature measurement was performed prior to sedation with a combination of detomidine hydrochloride (Domosedan, 0.01-0.02 mg/kg bwt i.v.) ${ }^{8}$ and butorphanol (Alvegesic, $0.005-0.01 \mathrm{mg} / \mathrm{kg}$ bwt i.v.) ${ }^{9}$ intravenous and intramuscular bolus $(0.02-0.04 \mathrm{mg} / \mathrm{kg}$ bwt i.m.) injections. Blood (serum and EDTA) was drawn and submitted for a complete blood count and chemistry panel. A microscopic agglutination test (MAT) for Leptospira antibodies was also routinely performed [32]. A total of nine serovars (L. bratislava, ${ }^{10} L$. icterohaemorrhagiae/copenhageni ${ }^{10}$, L. australis ${ }^{10}$, L. pomona $^{10}$, L. grippotyphosa ${ }^{10}$, L. autumnalis ${ }^{10}$, L.canicola $^{11}$ L. saxkoebing ${ }^{11}$, L.sejroe ${ }^{11}$ ) were evaluated ${ }^{10,11}$.

Following sedation, the horse's head was positioned atop a pair of pads placed on a mobile cart to increase stability. Local akinesia and analgesia (palpebral and the frontal nerve blocks) was achieved using $2 \%$ mepivacaine (Scandicain 2\%) ${ }^{12}$ [33]. Topical anesthetic ophthalmic solution (proparacaine HCL $0.5 \%)^{13}$ was applied as needed. The conjunctival fornices were irrigated with $1.0 \mathrm{ml}$ of a dilute baby shampoo solution ${ }^{14}(1 \mathrm{ml}$ of baby shampoo in $1 \mathrm{l}$ of balanced saline solution), $1.0 \mathrm{ml}$ of a $1.0 \%$ dilute iodine solution, ${ }^{15}$ and $1.0 \mathrm{ml}$ of balanced saline solution (Acrisol) ${ }^{4}$ [34].

Dorsal globe exposure was facilitated with either a Desmarres $^{16}$ or prototype eyelid retractor, ${ }^{17}$ and further enhanced by rotating the horse's head away from the examiner to exaggerate ventral globe rotation. The first 34 horses were treated with a $4 \mathrm{mg}$ injectable gentamicin solution containing preservatives (Genta100; $100 \mathrm{mg} / \mathrm{ml})^{9}$. All additional horses $(n=52)$ were treated with preservative-free gentamicin (PFG) (Gentamicin-ratiopharm, $160 \mathrm{mg} / 2 \mathrm{ml}$ SF) ${ }^{18}$ Undiluted gentamicin $(0.04 \mathrm{ml}$ Genta100 or $0.05 \mathrm{ml}$ PFG) 9,18 was drawn up in a 30- gauge needle/syringe combination (12 mm length, $1.0 \mathrm{ml}$ insulin syringe), and the IVGI was performed using headloupes (magnification) (Eschenbach MaxView with LED light source or headloupes with a separate head-mounted light source

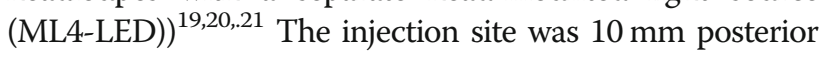
to the limbus at 12 o'clock. Injection was facilitated by applying gentle but steady pressure while slowly and deliberately rotating the needle in a clockwise manner with the needle directed toward the optic nerve head to avoid inadvertent contact with the lens. Aqueous paracentesis was then performed using a second insulin syringe at either the 11:00 o'clock (right eye, oculus dexter, OD) or 1:00 o'clock (left eye, oculus sinister, OS) positions. A total volume of 1 $\mathrm{ml}$ aqueous humor was aspirated. Aqueous humor and serum samples were refrigerated prior to transport to the laboratory. MAT tests for Leptospira titers were performed with the serum and aqueous humor, and real-time PCR was used for the detection of Leptospira DNA in the aqueous humor [35]. With the help of the C-value (dividing the aqueous humor Leptospira antibody titer by the serum Leptospira antibody titer), eyes were categorized into Leptospira "positive" (C-value greater than 3), "Leptospira suspicious" (C-value between 1 and 3) and "Leptospira negative" (C-value of 0 ) for statistical evaluation $[27,36]$.

\section{Post-injection therapy}

Post IVGI medical therapy consisted of topical antibiotics (Ofloxacin) ${ }^{22} \mathrm{q} 8 \mathrm{~h}$ for one week, and topical corticosteroids (Prednisolone acetate) ${ }^{23}$ or nonsteroidal anti-inflammatory drugs (NSAIDs) (Bromfenac) ${ }^{22}$ that were gradually tapered over the course of 4-8 weeks based on each horse's individual response to therapy. Either $1 \%$ tropicamide $^{24}$ or $1 \%$ atropine ${ }^{25}$ were applied topically for a variable duration to maintain or achieve mydriasis and to stabilize the blood aqueous barrier. Systemic NSAIDs (flunixin-meglumine, $0.55 \mathrm{mg} / \mathrm{kg}$, p.o., q12h) ${ }^{9}$ were also administered per os and gradually tapered-off over the course of 7 to 14 days. A prophylactic dose of 37\% omeprazole (Gastrogard, $2 \mathrm{mg} / \mathrm{kg}$ p.o.) ${ }^{26}$ was routinely administered orally, once daily while using systemic NSAIDs.

\section{Follow-up examination}

Following IVGI all eyes were immediately examined for the presence of peri-injection complications (subconjunctival or intracameral hemorrhage), and re-examined within $24 \mathrm{~h}$. Horses were monitored weekly for the first month or until medications were discontinued. Subsequent follow-up examinations were spaced further apart based on the horse's individual response to treatment. Inflammation was considered controlled if no signs of recurrent or persistent uveitis, independent of complications, were identified at any follow-up examination after medications had been discontinued. Particular attention was paid at all times to the possible development of post-injection complications (cataract formation/maturation, retinal degeneration).

\section{Data analysis}

All 86 eyes were evaluated for peri-injection complications (subconjunctival and intracameral hemorrhage), but only those with a minimum follow-up period of 30 days (59 eyes) were included in the post-injection statistical data evaluation. These latter eyes were monitored for signs of recurrent or persistent inflammation, as well as for the presence of additional complications or sequelae (e.g., cataract formation/progression and retinal degeneration). Correlation between the outcome (controlled, recurrent, or persistent inflammation), post-injection complications (no complications, cataract formation or maturation, and retinal degeneration), and possible influencing factors (breed, coat 
color, gender, clinical diagnosis with chronic or acute and recurrent or persistent, Leptospira status of the eye, Leptospira PCR, individual C-values for each Leptospira serovar, the combined C-value, the Leptospira serum and aqueous humor titer, response to topical medication prior to IVGI, severity of signs, frequencies of recurrence, gentamicin with preservatives, PFG, visual reflex tests, vision status prior to IVGI, miosis before IVGI, subconjunctival hemorrhage, intracameral hemorrhage and glaucoma prior to IVGI) were determined using a Pearson's chi-squared test or a Fisher's exact test. To avoid same-animal correlation, a single eye per horse was randomly selected for inclusion in the study from those receiving bilateral IVGI. Differences with $P \leq 0.05$ were considered significant. Results were calculated using computerized statistical software (IBM SPSS 23.0). ${ }^{27}$

\section{Endnotes}

${ }^{1}$ Kowa Company Ltd., Tokyo, Japan

${ }^{2}$ Keeler Instruments Inc., Broomall, Pennsylvania, USA

${ }^{3}$ Icare, Oy, Vantaa, Finland

${ }^{4}$ Alcon, Pharma GmbH, Freiburg im Breisgau, Germany

${ }^{5}$ Nikon GmbH, Düsseldorf, Germany

${ }^{6}$ Life Pixel, Mukilteo, Washington, USA

${ }^{7}$ Kruuse A/S, Langeskov, Denmark

${ }^{8}$ Pfizer Animal Health, Exton, Pennsylvania, USA

${ }^{9} \mathrm{CP}$-Pharma, Handelsges. mbH, Burdorf Germany

${ }^{10}$ Idexx Laboratories, Inc., Ludwigsburg, Germany

${ }^{11}$ Laboklin GmbH und Co.KG, Bad Kissingen, Germany

${ }^{12}$ AstraZeneca GmbH, Wedel, Germany

${ }^{13}$ Ursapharm Azneimittel GmbH, Saarbrücken, Saarland

${ }^{14}$ Johnson and Johnson GmbH, Neuss Germany

${ }^{15}$ aniMedica GmbH, Senden-Bösensell, Germany

${ }^{16}$ B.Braun Welsungen AG, Welsungen, Germany

${ }^{17}$ Eickemeyer-Medizintechnik für Tierärzte KG, Tuttlingen, Germany

${ }^{18}$ Ratiopharm GmbH, Ulm, Germany

${ }^{19}$ Eschenbach Optik GmbH, Nürnberg, Germany

${ }^{20}$ Zeiss, Jena, Germany

${ }^{21}$ Heine Optotechnik, Herrsching, Germany

${ }^{22}$ Bausch and Lomb GmbH., Berlin, Germany

${ }^{23}$ Dr. Winzer GmbH, Berlin, Germany

${ }^{24}$ Pharma Stulln GmbH, Stulln, Germany

${ }^{25}$ Römhild pharmacy, Diessen, Germany

${ }^{26}$ Merial GmbH, Hallbergmoos, Germany

${ }^{27}$ IBM, Armonk, New York, USA

\section{Abbreviations}

AH: Aqueous humor; CSI: Cyclosporine implant; ERG: Electroretinogram; ERU: Equine recurrent uveitis; HIK: Heterochromic iridocyclitis and keratitis; IVGI: Intravitreal gentamicin injection; MAT: Microscopic agglutination test; NSAID: Nonsteroidal anti-inflammatory drug; OCT: Optical coherence tomography; PFG: Preservative-free gentamicin; PLR: Pupillary light reflex; PPV: Pars plana vitrectomy; S: Serum

\section{Acknowledgements}

The authors would like to thank Drs. Denise Lindley and Marjorie Neaderland for providing the impetus for this study, and Drs. Tammy Miller Michau and Anne Wooldridge for reviewing earlier drafts of the manuscript.

\section{Funding}

None.

\section{Availability of data and materials}

The datasets used and/or analysed during the current study are available from the corresponding author (RJM) on reasonable request.

\section{Authors' contributions}

BMF: Data collection, manuscript preparation, revision and editing; RJM: Study design, data collection, manuscript preparation, revision and editing; SR: Statistical evaluation and manuscript revision; WB: Study design, manuscript preparation, revision and editing. All authors read and approved the final manuscript.

\section{Ethics approval and consent to participate}

Owners were educated on the various medical and surgical (i.e., PPV, CSI, and intravitreal injections) treatment options, and risks associated with each option. Verbal client consent to perform the IVGI was obtained following an in-depth discussion of potential complications including failure of the selected treatment option to control the disease, resulting in persistent/ recurrent inflammation with progression of ocular signs, and potential cataract maturation or development and retinal degeneration or detachment.

\section{Consent for publication}

not applicable.

\section{Competing interests}

The authors declare that they have no competing interests.

\section{Publisher's Note}

Springer Nature remains neutral with regard to jurisdictional claims in published maps and institutional affiliations.

\section{Author details}

'Department of Clinical Sciences, College of Veterinary Medicine, Auburn University, JT Vaughan Large Animal Teaching Hospital, 1500 Wire Road, Auburn, AL 36849-5540, USA. ${ }^{2}$ Chair of Anatomy, Histology and Embryology, Faculty of Veterinary Medicine, LMU, Munich, Germany. ${ }^{3}$ Faculty of Veterinary Medicine, University of Leipzig, Department for Horses, Leipzig, Germany.

Received: 16 August 2018 Accepted: 29 November 2018

Published online: 16 January 2019

References

1. Deeg CA, Thurau SR, Gerhards H, Ehrenhofer M, Wildner G, Kaspers B. Uveitis in horses induced by interphotoreceptor retinoid-binding protein is similar to the spontaneous disease. Eur J Immunol. 2002;32:2598-606.

2. Gilger BC, Deeg C. Equine recurrent uveitis. In: Gilger BC, editor. Equine ophthalmology, 2nd Edition. Missouri: Elsevier Science; 2010. p. 317-49.

3. Allbaugh RA. Equine recurrent uveitis: a review of clinical assessment and management. Equine Vet Educ. 2017;29:279-88.

4. Schwink KL. Equine Uveitis. Vet Clin North Am - Equine Pract. 1992;8: $557-74$

5. Miller TR, Whitley RD. Uveitis in horses. Mod Vet Pract. 1987;8:351-7.

6. Abrams KL, Brooks DE. Equine recurrent uveitis: current concepts in diagnosis and treatment. Equine Pract. 1990;12:27-35.

7. Rebhun WC. Diagnosis and treatment of equine uveitis. J Am Vet Med Assoc. 1979:175:803-8.

8. Gilger BC. Equine recurrent uveitis: the viewpoint from the USA. Equine Vet J. 2010;42(Suppl 37):57-61.

9. Werry $\mathrm{H}$, Gerhards H. Zur operativen Therapie der equinen rezidivierenden Uveitis (ERU). Tierärztl Prax. 1992;20:178-86.

10. Frühauf $B$, Ohnesorge B, Deegen $E$, Boevé $M$. Surgical management of equine recurrent uveitis with single port pars plana vitrectomy. Vet Ophthalmol. 1998;1:137-51. 
11. von Borstel M, von Oppen $T$, Glitz F, Frühauf B, Deegen E, Boevé MH, Ohnesorge B. Langzeitergebnisse der Pars plana Vitrektomie (double port) bei Equiner Rezidivierender Uveitis. Pferdeheilk. 2005;21:13-8.

12. Winterberg A, Gerhards H. Langzeitergebnisse der Pars-plana-Vitrektomie bei equiner rezidivierender Uveitis. Pferdeheilk. 1997;13:377-83.

13. Gilger BC, Wilkie DA, Clode AB, McMullen RJ, Utter ME, Komaromy AM, Brooks DE, Salmon JH. Long-term outcome after implantation of a suprachoroidal cyclosporine drug delivery device in horses with recurrent uveitis. Vet Ophthalmol. 2010;13:294-300.

14. Tömördy $E$, Hässig $M$, Spiess BM. The outcome of pars plana vitrectomy in horses with equine recurrent uveitis with regard to the presence or absence of intravitreal antibodies against various serovars of Leptospira interrogans. Pferdeheilk. 2010;26:251-4.

15. Gilger BC, Michau TM. Equine recurrent uveitis: new methods of management. Vet Clin North Am - Equine Pract. 2004;20:417-27.

16. Spiess BM. Equine recurrent uveitis: the European viewpoint. Equine Vet J. 2010;42(Suppl 37):50-6.

17. Gerding JC, Gilger BC. Prognosis and impact of equine recurrent uveitis. Equine Vet J. 2016:48:290-8.

18. Sandmeyer $L S$, Bauer BS, Feng CX. Equine recurrent uveitis in western Canada: a retrospective study. In: Dorothy Havemeyer equine ophthalmology symposium, Malahide, Ireland, June 2016. International equine ophthalmology consortium; 2016. p. 20-1.

19. Van KB, Rothova A, De VP. The pros and cons of intravitreal triamcinolone injections for uveitis and inflammatory cystoid macular edema. Ocul Immunol Inflamm. 2006;14:73-85.

20. Kok H, Lau C, Maycock N, McCluskey P, Lightman S. Outcome of intravitreal triamcinolone in uveitis. Ophthalmology. 2005;112:1916.e1-7.

21. Yi NY, Davis JL, Salmon JH, Gilger BC. Ocular distribution and toxicity of intravitreal injection of triamcinolone acetonide in normal equine eyes. Vet Ophthalmol. 2008;11(Suppl 1):15-9.

22. Baath J, Ells a L, Crichton a, Kherani a, Williams RG. Safety profile of intravitreal triamcinolone acetonide. J Ocul Pharmacol Ther. 2007;23: 304-10.

23. Douglas LC, Yi NY, Davis JL, Salmon JH, Gilger BC. Ocular toxicity and distribution of subconjunctival and intravitreal rapamycin in horses. J Vet Pharmacol Ther. 2008;31:511-6.

24. Wollanke B, Rohrbach BW, Gerhards H. Serum and vitreous humor antibody titers in and isolation of Leptospira interrogans from horses with recurrent uveitis. J Am Vet Med Assoc. 2001:219:795-800.

25. Pinard C. Gentamicin injection. In: $36^{\text {th }}$ annual meeting of the American College of Veterinary Ophthalmologists, Nashville, Tennessee, October 2005. Vet Ophthalmol. 2005:437-50

26. McMullen RJ, Fischer BM. Medical and Surgical Management of Equine Recurrent Uveitis. Vet Clin North Am-Equine Pract. 2017:33:465-81.

27. Goldmann HT, Witmer R. Antikörper im Kammerwasser. Ophthalmologica. 1954;127:323-30.

28. Romeike A, Brügmann M, Drommer W. Immunohistochemical studies in equine recurrent uveitis (ERU). Vet Pathol. 1998;35:515-26.

29. Kleinpeter A, Pohlmann A, Mütze M. Intravitreale Gentamicin-Injektion zur Therapie der equinen rezidivierenden Uveitis-Methode und Fallauswertung. Leipzig: Leipziger Tierärztekongress; 2014. p. 27-30.

30. Lam DL, Axtelle J, Rath S, Dyer A, Harrison B, Rogers C, Menon N, Van GRN. A Rayleigh scatter-based ocular flare analysis meter for flare photometry of the anterior chamber. Transl Vis Sci Technol. 2015:4:7.

31. Pinto NI, McMullen RJ, Linder KE, Cullen JM, Gilger BC. Clinical, histopathological and immunohistochemical characterization of a nove equine ocular disorder: Heterochromic iridocyclitis with secondary keratitis in adult horses. Vet Ophthalmol. 2015:18:443-56.

32. Brehm S, Weber A. Zum serologischen Nachweis von Leptospireninfektionen bei Rindern und Pferden mit Hilfe eines im Hande erhaltlichen Objektträgeragglutinationstestes. Der praktische Tierarzt. 1984; 65:835-41.

33. Gilger BC, Stoppini R. Equine ocular examination: routine and advanced diagnostic techniques. In: Gilger BC, editor. Equine ophthalmology, 2nd Edition. Missouri: Elsevier Science; 2011. p. 1-51.

34. Brooks DE, Matthews A, Clode AB. Disease of the cornea. In: Gilger BC, editor. Equine ophthalmology, 3rd Edition. Ames: John Wiley \& Sons, Inc.; 2017. p. 252-368.
35. Stoddard RA, Gee JE, Wilkins PP, McCaustland K, Hoffmaster AR. Detection of pathogenic Leptospira spp. through TaqMan polymerase chain reaction targeting the LipL32 gene. Diagn Microbiol Infect Dis. 2009;64:247-55.

36. De Groot-Mijnes JD, Rothova A, van Loon AM, Schuller M, ten D-VLNH, de BJH, Schuurman R, Weersink AJL. Polymerase chain reaction and Goldmann-Witmer coefficient analysis are complimentary for the diagnosis of infectious uveitis. Am Journal Ophthalmol. 2006;141:313-8.
Ready to submit your research? Choose BMC and benefit from:

- fast, convenient online submission

- thorough peer review by experienced researchers in your field

- rapid publication on acceptance

- support for research data, including large and complex data types

- gold Open Access which fosters wider collaboration and increased citations

- maximum visibility for your research: over $100 \mathrm{M}$ website views per year

At $\mathrm{BMC}$, research is always in progress.

Learn more biomedcentral.com/submissions 